\title{
Uma história da primeira página: 50 anos de primeiras páginas de jornais brasileiros entre 1875 e $1925^{1}$
}

Adriana BARSOTTI ${ }^{2}$

\begin{abstract}
Resumo:
Este artigo mapeia as origens da primeira página moderna nos jornais brasileiros, com base na análise de 407 capas de cinco periódicos influentes no período compreendido entre 1875 e 1925: O Paiz, Gazeta de Notícias, Correio da Manhã, Jornal do Brasil e $O$ Estado de S. Paulo. A pesquisa revelou que as primeiras manchetes surgiram entre 1905 e 1906 em quatro dos títulos e que, em 1915, as capas com manchetes, títulos, fotos e ilustrações já eram uma realidade na Gazeta de Notícias e no Correio da Manhã. Em 1925, O Paiz também seguia o padrão. O Estado de S.Paulo e o Jornal do Brasil fogem à regra na segunda década do século passado, validando o pressuposto teórico do estudo, segundo o qual a história se faz em meio a múltiplas temporalidades, rupturas e descontinuidades e que, portanto, não haveria uma data fundadora em comum para a incorporação da primeira página moderna na história do jornalismo brasileiro.
\end{abstract}

Palavras-chave: primeiras páginas; história do jornalismo brasileiro; manchetes.

\section{A history of the front page: 50 years of Brazilian dailies' front pages between 1875 and 1925}

\begin{abstract}
:
This article maps the origins of the modern front page by Brazilian newspapers, based on the analysis of 407 pages one of five influential dailies between 1875 and 1925: O Paiz, Gazeta de Notícias, Correio da Manhã, Jornal do Brasil and $O$ Estado de S. Paulo. The research revealed that the first headlines appeared between 1905 and 1906 in four of the periodicals and that, in 1915, the front pages with headlines, titles, photos and illustrations were already a reality in Gazeta de Notícias and in Correio da Manhã. In 1925, O Paiz also followed the pattern. O Estado de S.Paulo and Jornal do Brasil were not the norm in the second decade of the last century, validating the theoretical assumption of the study, according to which history is made in the midst of multiple temporalities, ruptures and discontinuities and, therefore, there wouldn't be a unique founding date for the adoption of the modern front page in the history of Brazilian journalism.
\end{abstract}

Keywords: front pages; history of Brazilian journalism; headlines.

\section{Una historia de la primera pagina: 50 años de primeras paginas de periódicos brasileños entre 1875 y 1925}

Resumen:

Este artículo traza los orígenes de la primera pagina moderna por los periódicos brasileños, basada en el análisis de 407 portadas de cinco publicaciones influyentes entre 1875 y 1925: O Paiz, Gazeta de Notícias, Correio da Manhã, Jornal do Brasil y $O$ Estado de $S$. Paulo. La investigación reveló que los primeros titulares aparecieron entre 1905 y 1906 en cuatro de los periódicos y que, en 1915, las portadas con titulares, títulos, fotos e ilustraciones ya eran una realidad en Gazeta de Notícias y en Correio da Manhã. En 1925, O Paiz también siguió el estándar. O Estado de S. Paulo y Jornal do Brasil fueron excepciones en la segunda década del siglo pasado, validando la suposición teórica del estudio, según el cual la historia se hace en medio de múltiples temporalidades, rupturas y discontinuidades y, por lo tanto, no habría una fecha de fundación estándar para la

\footnotetext{
${ }^{1} \mathrm{O}$ artigo é um resumo de um capítulo de tese de doutorado já defendida pela autora (BARSOTTI, 2017).

2 Doutora em Comunicação Social pela Pontifícia Universidade Católica do Rio de Janeiro (PUC-Rio). Professora Adjunta do Departamento de Comunicação da Universidade Federal Fluminense e Professora do Programa de Pós-Graduação em Mídia e Cotidiano (PPGMC-UFF).
}

Revista Brasileira de História da Mídia, São Paulo, v. 10, n. 2, p. 180-201, jul./dez. 2021 
adopción de la práctica en los periódicos en la historia del periodismo brasileño.

Palabras clave: primera pagina; historia del periodismo brasileño; titulares.

\section{Introdução}

"Nenhum estudo sobre o conteúdo dos jornais será completo sem uma análise de suas primeiras páginas", escreveu Armstrong, em 1926, depois de conduzir uma pesquisa de 50 anos sobre as transformações nas capas de jornais norte-americanos. "Pela primeira página, um jornal é julgado. O tom da primeira página é uma medida bem precisa do que é o jornal como um todo" (ARMSTRONG, 1926, p. 17, tradução da autora). ${ }^{3}$

As observações de Armstrong são de um período de intensas transformações na imprensa americana, quando, dentre outras mudanças, a primeira página passou a ser dedicada a notícias, com manchetes, chamadas, fotos e ilustrações. O paradigma da primeira página moderna foi uma invenção da penny press americana - representada pelos jornais vendidos a um centavo -, a partir da década de 1830, quando os diários passaram a se massificar naquele país (SCHUDSON, 2010). No Brasil, a adoção do paradigma da primeira página moderna aconteceu nas primeiras duas décadas do século XX. Até essa época, os artigos de fundo e os folhetins, novidade que fora lançada pela imprensa francesa, tinham lugar privilegiado nas capas dos periódicos brasileiros.

Este artigo se propõe a apresentar as origens da primeira página moderna no Brasil a partir da pesquisa de primeiras páginas de cinco jornais brasileiros no período de 50 anos. A análise teve como ponto de partida o estudo de Armstrong Origens do jornal moderno: um estudo comparativo dos diários de St. Louis de 1875 a 1925 (ARMSTRONG, 1926). A partir dela, a tentativa foi traçar uma espécie de "arqueologia" - aludindo ao conceito de Foucault (2015) - das primeiras páginas modernas de cinco jornais brasileiros influentes no mesmo período pesquisado por Armstrong: O Paiz, Gazeta de Notícias, Correio da Manhã, Jornal do Brasil e $O$ Estado de S. Paulo. A metodologia incluiu a análise de conteúdo de 407 primeiras páginas desses periódicos, além de revisão bibliográfica.

\footnotetext{
${ }^{3}$ No original, em inglês: "No study of newspaper content is complete without an analysis of the front page. By the front page a newspaper is judged, and rightly so. The tone of the front page is a fairly accurate criterion of the whole paper" (ARMSTRONG, 1926, p. 17).
} 


\section{Percurso teórico}

A “arqueologia do saber", tal como propõe Foucault (2015), rompe com a noção de linearidade, evolução e progresso e busca investigar os sistemas de pensamento a partir das práticas discursivas. O teórico critica o que chama de "história global", que representa o paradigma da modernidade, por supor que exista um "sistema de relações homogêneas" entre todos os acontecimentos ocorridos dentro de um tempo e espaço definidos (FOUCAULT, 2015, p. 11-12). Em seu lugar, faria mais sentido uma história de rupturas e descontinuidades (FOUCAULT, 2015). A opção neste artigo por "uma história" das primeiras páginas se articula com os conceitos sobre temporalidades múltiplas que coexistem em determinados períodos de tempo, tal como apontaram Foucault (2015), Pomian (1984) e Koselleck (2006).

Há que se considerar também que a experiência temporal é narrada. Para Ricoeur (1994), a história se constrói por meio das narrativas. Assim como a história, o jornalismo também é feito de narrativas. O jornalista seleciona um conjunto de acontecimentos e constrói narrativas. Pelas primeiras páginas dos jornais do período, os relatos dos acontecimentos revelam o espírito de uma época, mas também ajudam a reconstituir, por meio de fragmentos, “uma história” das primeiras páginas dos periódicos.

Apesar de o corpus da pesquisa estar ancorado nos jornais impressos, o estudo buscou relativizar a superioridade da palavra escrita e se vale do conceito de performance proposto por Zumthor (2014). Para ele, o texto se tece por meio das relações humanas em que a voz, o corpo e a presença desempenham papel fundamental. Zumthor (2014, p. 60) define "performance" como o ato da comunicação, em que voz e corpo adquirem uma dimensão sensorial. Foi também levando em conta a oralidade que Barbosa (2013, p.152-195) notou em seus estudos sobre a imprensa brasileira que, numa população em que $80 \%$ eram analfabetos, ${ }^{4}$ "lia-se vendo imagens".

É também preciso enxergar, no contexto de surgimento das primeiras páginas modernas no jornalismo brasileiro, um cenário reconfigurado pelo "novo horizonte técnico" (SUSSEKIND, 1987) que caracterizava o período pesquisado, com a difusão da fotografia, da telefonia, do cinematógrafo, do fonógrafo e a incorporação de novas técnicas de impressão de textos e fotos.

Arautos e porta-vozes da modernidade, os jornais também passam por transformações técnicas em seu processo de produção nas primeiras décadas do século passado. São

\footnotetext{
${ }^{4}$ O dado é do Censo de 1890, citado por Barbosa (2013, p. 152).
} 
introduzidas novas máquinas impressoras com capacidade de rodar de 10 a 20 mil exemplares por hora, máquinas fotográficas e métodos fotoquímicos para a impressão em cores. Os periódicos adotam ainda o serviço telegráfico, valorizando a rapidez (BARBOSA, 2007).

Nas primeiras páginas de jornais, o mundo aparece fragmentado, condensado, acelerado e desconectado, tal qual a vida moderna. Matheus (2013) mostrou como telegramas, cartas e o malote dos correios coexistiam como fontes de informação nas páginas de jornais, o que contribuía para a miscelânea de temporalidades. Úteis para entender as transformações do período pesquisado são os conceitos de colagem (GIDDENS, 2002) e justaposição (ANDERSON, 1991). Anderson (1991) notou que os acontecimentos díspares e fragmentados estampados nas primeiras páginas são conectados apenas pela coincidência temporal.

Giddens (2002) sublinha que a mídia introduziu, na modernidade, o efeito colagem e passou a incluir, na consciência cotidiana, eventos até então distantes. Assim como Anderson (1991), ele também usa o termo “justaposição" para se referir à apresentação de notícias pela mídia, que reorganizaria o tempo e o espaço. As histórias apresentadas, sustenta, não são uma única narrativa, mas expressam "ordenamentos típicos de consequencialidade" (GIDDENS, 2002, p. 31).

Uma nova cultura visual de massa no Brasil estava em construção desde a segunda metade do século XIX. Sontag (1981, p. 147) observa que uma sociedade se torna "moderna" quando uma de suas principais atividades passa a ser a "produção e o consumo de imagens". Barbosa (2013, p. 169) nota que, no início do século XX, há a emergência de múltiplas linguagens que se cruzam: a dos sons e vozes do burburinho das ruas; a informação verbal dos impressos; e a visual, "complementar ao texto e como algo que passa a substitui-lo". A comunicação é, sobretudo, sensorial.

Mas as sensações não eram somente despertadas no ato da "leitura" de jornais. A incorporação do noticiário policial no período também proporcionou um "fluxo sensacional", como o chama Barbosa (2007), por meio de notícias sobre crimes e tragédias da vida cotidiana, o que ajudou a construir os elos entre a imprensa e os leitores. Por trás das situações particulares, narradas em detalhes nas páginas dos jornais, há um arcabouço prévio de significações, com uma temática que repete "os mitos, as figurações, as representações que falam de crimes e mortes violentas, de milagres, de desastres" (BARBOSA, 2007, p. 53). 


\section{Metodologia}

Para investigar as origens da primeira página no jornalismo brasileiro, foi realizada uma análise de conteúdo (FONSECA JR., 2015) das primeiras páginas de cinco dos títulos de maior circulação e relevância no mesmo período pesquisado por Amstrong (1875-1925). Os periódicos escolhidos foram O Paiz, Gazeta de Notícias, Correio da Manhã, Jornal do Brasil e $O$ Estado de S. Paulo..$^{5}$ Para se chegar aos títulos, foram consideradas as referências feitas a eles por Barbosa (2007) e Sodré (1999). Dos cinco jornais, apenas dois circularam durante os 50 anos pesquisados: O Estado de S. Paulo, fundado em 1875 e ainda em circulação, e Gazeta de Notícias, também de 1875 e que foi impresso até a década de $1960 .{ }^{6}$ O Paiz circulou entre 1884 e 1934 e o Correio da Manhã, entre 1901 e 1974. O Jornal do Brasil, de 1891, mantém apenas sua versão on-line (LEAL, 2015).

Citando Olavo Bilac, Barbosa indica que as cinco mais importantes folhas do Rio no início do século XX eram o Jornal do Brasil, o Jornal do Commercio, a Gazeta de Notícias, o Correio da Manhã e o Paiz, que, juntas, teriam uma tiragem de 150 mil exemplares numa cidade que, à época, tinha 600 mil habitantes (BILAC, 1994 apud BARBOSA, 2007). A autora considera que foram esses periódicos os responsáveis pela criação do jornalismo de informação no país.

O Estado de S. Paulo foi incluído na pesquisa por duas de suas características inovadoras para a época. A primeira delas foi ter utilizado buzinas para vender os jornais nas ruas. $^{7}$ A segunda foi ter enviado, em 1888, "numa iniciativa pioneira, que anuncia novos métodos de imprensa", Euclides da Cunha para cobrir a Guerra de Canudos, o que resultaria no clássico Os sertões (SODRÉ, 1999, p. 269).

Ao todo, foram analisadas 407 primeiras páginas desses cinco títulos na Hemeroteca Digital da Biblioteca Nacional e no Acervo de O Estado de S. Paulo. Numa primeira etapa, foram pesquisadas 47 delas: de dez em dez anos, desde 1875 até 1925, as capas foram observadas em duas datas: 10 de março e 10 de outubro. Embora os títulos tenham sido intencionalmente selecionados, a escolha das datas foi aleatória (WIMMER; DOMINICK, 2011, p. 62).

\footnotetext{
${ }^{5}$ Embora tenha sido um dos mais influentes da época, o Jornal do Commercio foi excluído da amostragem por não possuir acervo digitalizado.

${ }^{6} \mathrm{Na}$ Hemeroteca Digital da Biblioteca Nacional, o último exemplar disponível do periódico data de 30 de dezembro de 1956. Entretanto, ele circulou até a década de 1960, com poucos exemplares (LEAL, 2015).

${ }^{7}$ Note-se que o primeiro jornal a adotar a venda avulsa no país nas ruas foi a Gazeta de Notícias, em 1875 (BARBOSA, 2013).
} 
$\mathrm{Na}$ etapa inicial, foram coletadas 12 primeiras páginas de $O$ Estado de S. Paulo, 11 da Gazeta de Notícias, 10 de O Paiz, 8 do Jornal do Brasil e 6 do Correio da Manhã. ${ }^{8}$ Em uma primeira análise, foi observado que as mudanças nas primeiras páginas, que praticamente se mantinham inalteradas desde a primeira década pesquisada, foram muito significativas entre 1905 e 1915. Daí a necessidade de investigar mais a fundo o período. Wimmer e Dominick (2011) propõem a amostragem de múltiplos estágios toda vez que o pesquisador se depara com a necessidade de aprofundar determinado aspecto.

Portanto, uma segunda coleta foi feita da seguinte maneira: em 1905 e 1906, foram reunidas 36 primeiras páginas por ano dos cinco títulos: a cada dez edições, a partir da primeira do ano, a última era selecionada. Na nova amostragem, foram obtidas mais 360 capas. Foram desconsideradas as edições de domingo para não enviesar os resultados, tendo em vista que tais edições sempre foram menos factuais. A coleta foi interrompida no fim de 1906, pois a pesquisa constatou que aquele fora o ano em que as manchetes passaram a ser mais frequentes, como será detalhado a seguir.

\section{E os jornais começam a gritar: a oralidade e as imagens técnicas}

De 1875 a 1895, as primeiras páginas dos jornais passam por transformações muito sutis. O Estado de S. Paulo, a Gazeta de Notícias e o Jornal do Brasil publicam folhetins na capa. As notícias eram agrupadas em seções temáticas, cada uma delas em uma coluna. Quanto mais para o fim do século, mais temas são inseridos, configurando os efeitos de colagem (GIDDENS, 2002) e justaposição (ANDERSON, 1991). Além disso, os jornais crescem em número de colunas, todos chegando a 1895 com oito na primeira página. Para alcançar um público mais vasto, era necessário aumentar a variedade de assuntos.

A Gazeta de Notícias, em seu primeiro ano, promove concursos para seus leitores (o “Logogrifos e as Charadas"), como pode ser observado na capa de 10 de outubro de 1875 . No periódico, o espaço na primeira página para notícias sobre crimes é garantido na seção "Jury da Corte". Outras três seções foram publicadas na primeira página desse mesmo dia, além do folhetim: "Telegrammas", "Multas Municipais" e "Charadas". Algumas seções são fixas, como o "Jury da Corte" e "Telegrammas". Já as demais, de acordo com os acontecimentos do dia (ver Figura 1).

\footnotetext{
${ }^{8} \mathrm{~A}$ discrepância se deve às diferentes datas em que estes jornais passaram a circular, como já apontado.
} 
A seção "Telegrammas", publicada nas primeiras páginas, era comum aos quatro diários em circulação na época, analisados nesta pesquisa. ${ }^{9} \mathrm{Na}$ seção, eram publicadas desde a chegada e partida de navios e correios postais até muitas notícias sem vinculação alguma com a realidade brasileira, como a que figurava na capa de $O$ Paiz de 10 de março de 1895: "De Londres - Está seriamente infermo Lord Fowler”. Matheus (2013) mostra como telegramas, cartas e o malote dos correios eram utilizados indistintamente como fontes de informação nas seções "Telegrammas" dos jornais da época. Nessas seções, várias camadas temporais eram superpostas. Barbosa (2013) sublinha que os periódicos ajudaram a construir um novo sentido para o tempo e mesmo a contribuir para marcá-lo a partir do século XIX, em uma época caracterizada pela aceleração.

Um tempo mais acelerado, ditado pelo ritmo do relógio que marca minutos e horas também se deixa transparecer nos periódicos que incluem como novidades, ao lado das notícias de um mundo político em crise, o movimento de entrada e saída dos navios dos portos (BARBOSA, 2013, p. 59).

Figura 1 - Primeira página do jornal Gazeta de Notícias de 10 outubro de 1875

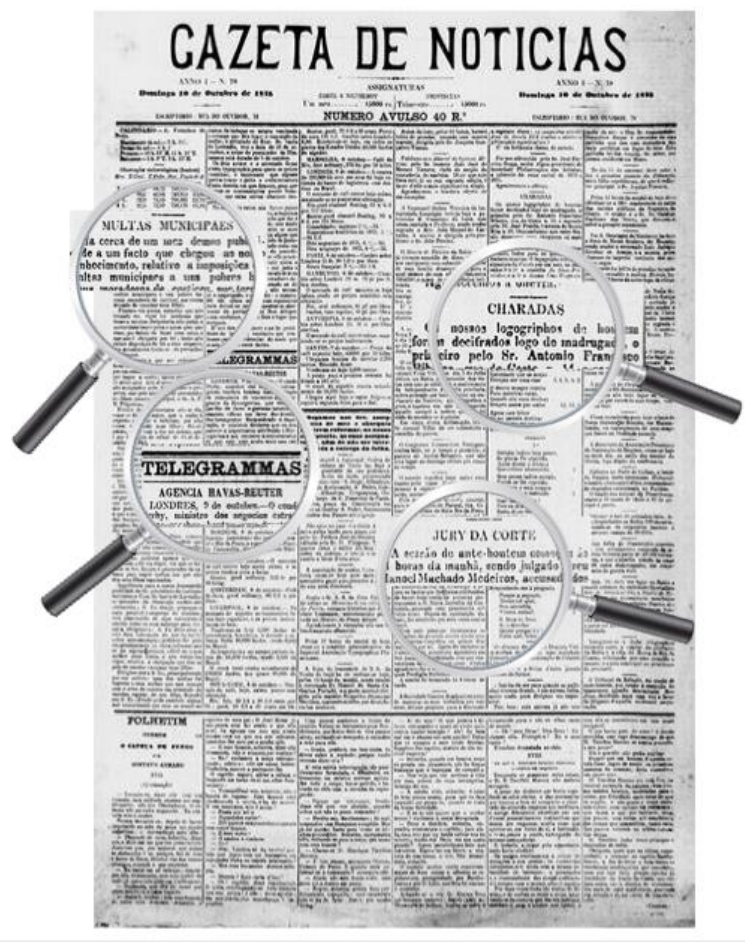

Fonte: Elaboração da autora a partir da Hemeroteca Digital da Biblioteca Nacional

\footnotetext{
${ }^{9}$ O Correio da Manhã só seria lançado em 1901.
} 
Na primeira década analisada (1875-1885), chama atenção a posição de porta-voz das queixas do povo assumida pelos jornais Gazeta de Notícias, O Paiz e Jornal do Brasil, em suas primeiras páginas. Na edição da Gazeta de Notícias de 10 de outubro de 1875, noticia-se na capa, sob a seção "Multas Municipais", que moradores de cortiços foram autuados por não terem vacinado seus filhos, mas alerta-se para o fato de não existir lei municipal para tanto. "Não censuramos a multa, não consideramos vexatória a imposição da vacina, pedimos apenas que seja publicada a lei em vigor”, clama o jornal (MULTAS..., 10 out. 1875, p. 1). Nota Barbosa que os jornais se estabeleciam como "o único intermediário possível” entre o público, excluído e sem direitos de cidadão, e o poder público" (BARBOSA, 2005, p. 56).

A seção "Marechal Floriano", publicado na capa de O Paiz de 10 de março de 1895, revela outra prática dos jornais da época: as críticas mútuas e a autorreferenciação. "Sobre o estado de saúde do ilustre Marechal Floriano deram-nos ontem informações o Jornal do Commercio e a Gazeta de Notícias" (MARECHAL..., 10 mar. 1895, p. 1) . Era comum os jornais da época republicarem notícias de outros, dando-lhes o crédito. Mas O Paiz, no caso em questão, aproveitou para tripudiar seus adversários:

Que ambos os jornais conhecem bem o estado de saúde do benemérito enfermo vê-se logo pela concordância das informações. Escreve o Jornal: 'informam-nos que não é lisonjeiro o estado de saúde do Sr. Marechal Floriano Peixoto. Sr. Ex. não tem conseguido melhoras em Cambuquira, de cujas águas não tem podido fazer uso regular'. Escreve a Gazeta: sabemos de fonte segura que tem passado melhor dos seus incômodos, graças às aguas e ao clima de Cambuquira'. Dedução: o marechal Floriano não está melhor nem pior, antes pelo contrário (MARECHAL..., 10 mar. 1895, p. 1).

Além de serem porta-vozes do público, os jornais também queriam sê-lo das classes dominantes. A reprodução de atos publicados no Diário Oficial indiscriminadamente nas primeiras páginas reforçava as relações com o poder: desde a ida do imperador Pedro II ao Colégio Pedro II para assistir a uma aula até licenças concedidas a funcionários públicos e nomeações, conforme publicado no Jornal do Brasil (NOTICIÁRIO, 10 mar. 1905, p. 1). Era chamada de "Noticiário" o nome da seção com os atos do D.O. tanto em O Paiz quanto no Jornal do Brasil.

A virada do século XIX para o século XX, compreendendo aqui o período entre 1895 e 1905, entretanto, traria novidades às primeiras páginas. Para Barbosa (2013), surge o que 
podemos chamar de imprensa de grande tiragem no país. Considerando o número de exemplares e a população da época, já mencionados, um a cada quatro habitantes da capital tinha contato direto com os periódicos. Sem contar aqueles que o tinham por terceiros, por meio da comunicação oral, fenômeno a que Zumthor (2014) chama de "performance".

No Brasil, a aproximação com a linguagem oral foi essencial para a sedução do público analfabeto ou pouco familiarizado com as letras. Nota Barbosa $(2013$, p.199) que o emprego de estratégias redacionais, como a publicação de páginas inteiras de ilustrações, fotos e tipologias fortes na primeira página, fez com que "grupos excluídos da sociedade se tornassem leitores extensivos dessas publicações".

A edição da primeira página do dia 11 de outubro de 1905 do Jornal do Brasil é emblemática de tais estratégias. Sob o título "Terremotos na Calábria", em quatro colunas, o diário publicou nove fotos sobre os tremores na Itália, embora com algum atraso. Os terremotos tinham acontecido mais de um mês antes, no dia 8 de setembro daquele ano. A notícia fora publicada pela primeira vez na capa do Jornal do Brasil no dia 3 de outubro, em duas colunas, com o mesmo título ("Terremotos na Calábria"), em reportagem enviada pelo correspondente na Itália. Aparecia com atraso de 25 dias em relação ao acontecimento, confirmando a convivência entre as temporalidades nas primeiras páginas (MATHEUS, 2013).

Abaixo do título sobre a primeira notícia acerca dos terremotos na Calábria, no Jornal do Brasil, já é possível vislumbrar um esboço de subtítulo, em tópicos distribuídos por quatro linhas: "20.000 pessoas sem abrigo - Cidades arrasadas - Tremendo Cataclismo - Cenas aterradoras" (TERREMOTOS..., 3 out. 1905, p. 1). A mesma estratégia foi observada nas edições da Gazeta de Notícias de 1905.

Conforme observa Barbosa (2007, p. 43), “o estilo entrecortado do texto faz supor um leitor titubeante seguindo as letras impressas das notícias de crimes e tragédias do cotidiano que se espalham por todo o jornal”. Imagens também começam a ser utilizadas para dar suporte ao texto, proporcionando uma mistura de linguagens que fazia com que os periódicos fossem lidos como "coisa visual” (BARBOSA, 2013, p. 150). Exemplo disso é a primeira página do Jornal do Brasil do dia 10 de março de 1905. A notícia "Homem ao mar", sobre o afogamento de um trabalhador do porto, traz uma ilustração em duas colunas de um homem morto, estirado no chão (ver Figura 2). 
Figura 2 - Primeira página do Jornal do Brasil de 10 março de 1905

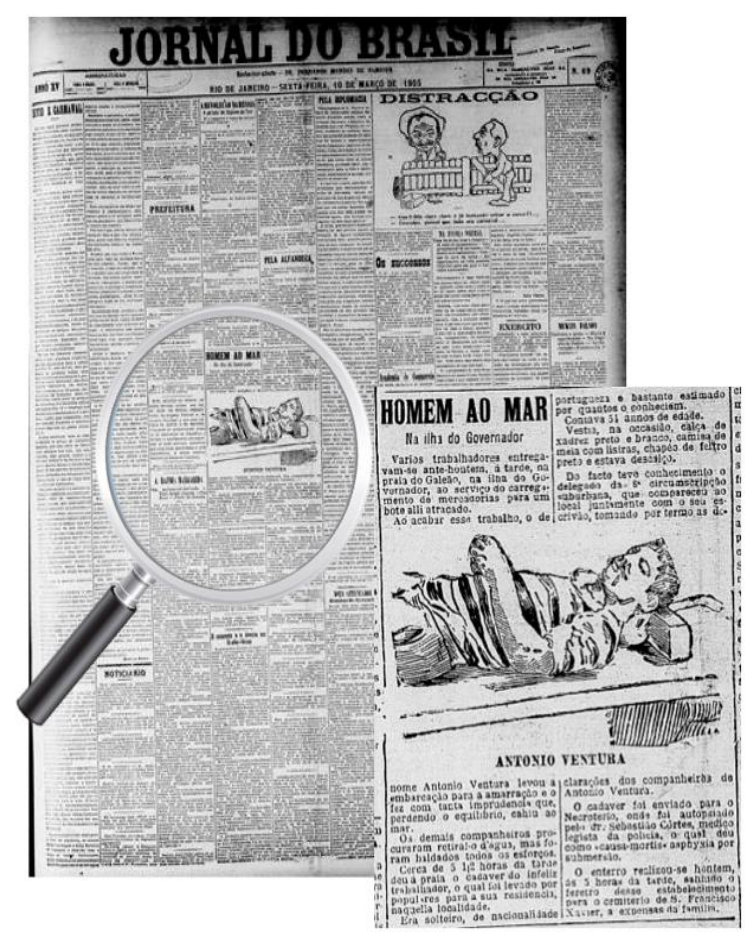

Fonte: Elaboração da autora a partir de imagem da Hemeroteca Digital da Biblioteca Nacional

Como principais mudanças do período entre 1895 e 1905, nota-se que os folhetins vão perdendo espaço na primeira página - apenas no Correio da Manhã, lançado em 1901, ele ainda é publicado na primeira página. Os artigos de fundo continuam sendo impressos regularmente na capa em quase todos os jornais analisados - somente no Jornal do Brasil eles são eventuais - e as fotos e ilustrações passam a ser utilizadas com mais frequência, com destaque para o Jornal do Brasil. O Estado de S. Paulo e o Jornal do Brasil, que aumentam para dez o número de colunas em suas capas.

Outro destaque do período é o espaço que a publicidade começa a conquistar nas primeiras páginas de alguns jornais. O Correio da Manhã e o Estado de S. Paulo trazem pequenos anúncios de uma coluna em suas primeiras páginas. No dia 10 de março de 1905, o Correio da Manhã publicou oito anúncios de uma coluna na capa. Os produtos anunciados eram perfumes, tecidos e bebidas (ver Figura 3). 
Figura 3 - Anúncios na primeira página do jornal Correio da Manhã de 10 de março de 1905

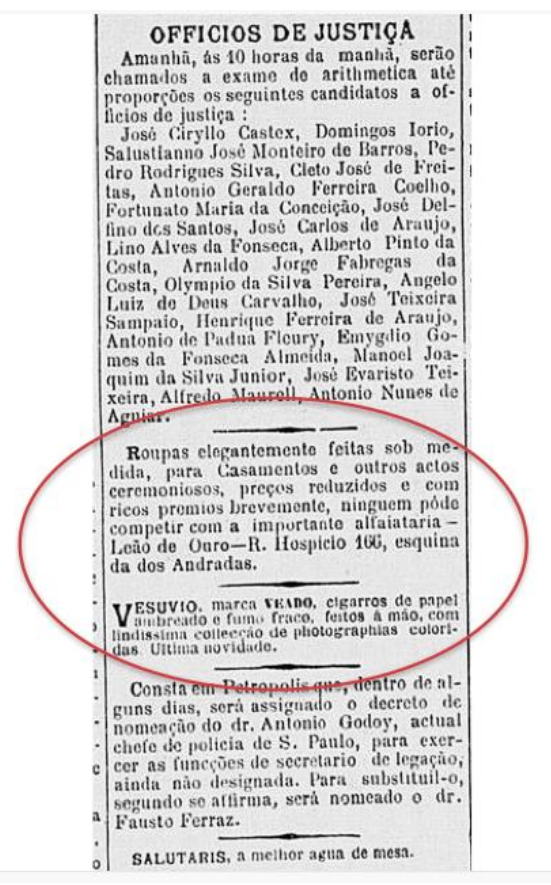

Fonte:Elaboração da autora a partir de imagem da Hemeroteca Digital da Biblioteca Nacional

Nas décadas seguintes, os anúncios aumentariam de tamanho e frequência. Nas edições de $O$ Estado de S. Paulo de 1925, peças publicitárias de carro e trator chegariam a ocupar toda a primeira página, e anúncios de duas e três colunas passariam a ser mais recorrentes. ${ }^{10}$ Já o Jornal do Brasil passaria a dedicar sua capa inteiramente aos classificados. Eram anúncios à procura de empregadas domésticas, como amas de leite, amas secas, lavadeiras e cozinheiras, o que lhe valeria o apelido de "jornal das cozinheiras" (RIBEIRO, 2007). A dedicação exclusiva da primeira página aos anúncios, consequência de uma grave crise financeira, perduraria até o final da década de 1950.

De maneira geral, no período entre 1895 e 1905, as notícias na primeira página ainda eram publicadas de forma uniforme, sem hierarquização. O padrão continuava sendo a diagramação delas em uma coluna, agrupadas por seções. Na edição do Jornal do Brasil de 11 de outubro de 1905, em uma coluna, publicada na seção "Noticiário", lê-se uma informação que somente décadas depois adquiriria o status de denúncia no jornalismo: "A comissão de finanças da Câmara dos Deputados assinou ontem o projeto que equipara os vencimentos dos diretores do Tribunal de Contas aos dos juízes da corte de Apelação" (NOTICIÁRIO, 11 out. 1905, p. 1).

\footnotetext{
${ }^{10} \mathrm{Na}$ primeira página de 10 de outubro de 1925 , uma publicidade de automóvel ocupou a maior parte da capa, em cinco colunas, e houve ainda outros três anúncios de duas colunas na mesma página.
} 
A princípio, pode-se julgar, pelo modo como os acontecimentos acima foram narrados, que o ideal da objetividade jornalística ainda estava longe de ser atingido, o que só aconteceria meio século depois, na visão de Ribeiro (2007). Para ela, na década de 1950, o modelo norte-americano se implantou de maneira hegemônica no jornalismo nacional, com a adoção de técnicas de reportagem consagradas pela imprensa americana. Entretanto, Barbosa (2007) nota que o mito da objetividade teve suas bases construídas na virada do século XIX para o XX. De fato, o próprio título da seção- "Noticiário" - já revelava um desejo cada vez maior por informação, seja qual fosse sua natureza.

\section{As primeiras manchetes e o "fluxo sensacional"}

Foi percebendo uma tendência de se publicar as notícias com mais destaque na primeira página que a pesquisa se ateve aos anos de 1905 e 1906. Na nova amostragem, ainda era raro uma notícia aparecer em mais de uma coluna, em 1905. Naquele ano, isso aconteceu em 11\% das vezes na Gazeta de Notícias, no Correio da Manhã e em O Paiz. No Jornal do Brasil, a ocorrência foi menor: menos de 5\%. Já em 1906, tornou-se uma prática mais regular: foram impressas manchetes em pelo menos duas colunas em $58 \%$ das edições selecionadas na amostragem da Gazeta de Notícias, 44\% nas de O Paiz, 33\% nas do Jornal do Brasil e 22\% nas do Correio da Manhã. Nas edições de O Estado de S.Paulo não ocorreram mudanças.

É possível afirmar que em 1905 e 1906 surgiram as primeiras manchetes com alguma regularidade nos jornais brasileiros, com destaque para a Gazeta de Notícias e O Paiz, apesar das disparidades entre os periódicos analisados. ${ }^{11}$ Aos poucos, a manchete viria a ocupar todas as colunas das capas, como no dia 29 de outubro de 1906, quando o Correio da Manhã publicou, em suas sete colunas, no alto da primeira página: "Noite trágica". Abaixo, três linhas de subtítulo: "Duplo estrangulamento e roubo, Crime Hediondo, Carletto preso!" e mais onze linhas de tópicos frasais com o resumo da notícia, que ocupou todo o espaço da capa (NOITE..., 29 out. 1906, p. 1). Na notícia, lê-se que Eugênio Rocca e Carletto tentaram assaltar a joalheria em que trabalhavam. Os sobrinhos do dono chegaram no exato momento e foram estrangulados pelos assaltantes. A manchete em sete colunas do Correio da Manhã com a notícia sobre o episódio, acima mencionada, foi publicada 14 dias depois de ele ter ocorrido e deveu-se ao fato de Carletto ter sido preso (ver Figura 4).

\footnotetext{
${ }^{11}$ No dia 16 de novembro de 1889 , O Estado de S. Paulo inovou ao dedicar a página inteira à manchete "Viva a República!". Entretanto, tais situações eram a exceção no período.
}

Revista Brasileira de História da Mídia, São Paulo, v. 10, n. 2, p. 180-201, jul./dez. 2021191 
Figura 4 - Primeira página do jornal Correio da Manhã de 29 de outubro de 1906

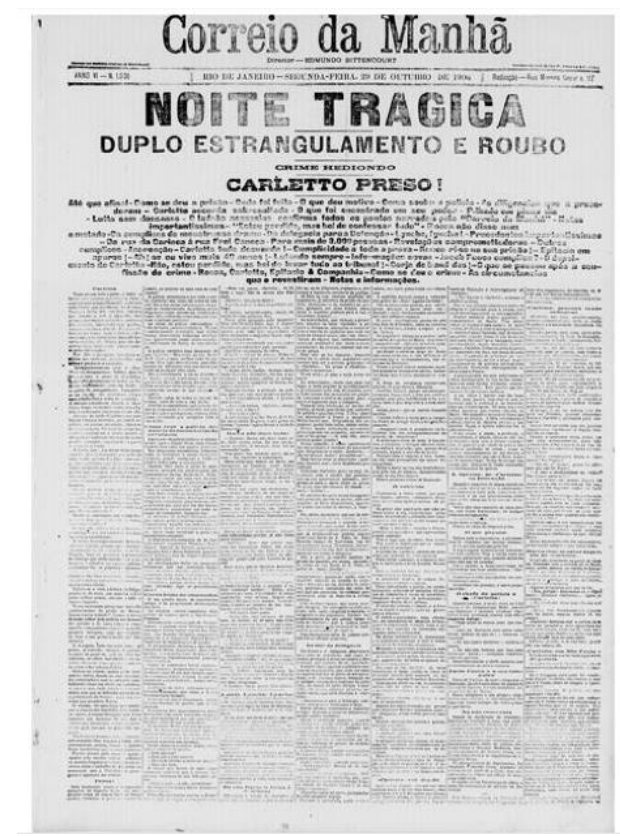

Fonte: Imagem da Hemeroteca Digital da Biblioteca Nacional

A primeira notícia sobre o crime fora estampada em duas colunas no dia seguinte ao estrangulamento, no dia 16 de outubro de 1906, com a mesma manchete "Noite trágica". Essa manchete foi repetida oito vezes entre os dias 16 e 29, variando entre uma e sete colunas, para abordar os acontecimentos subsequentes, como pistas, novos envolvidos, enfim, o desenrolar das investigações. Os subtítulos "Duplo estrangulamento e roubo" e "Crime hediondo" também foram republicados oito vezes.

Tal qual nos folhetins, os títulos se sucediam repetidamente. Na Gazeta de Notícias e em O Paiz, observa-se a adoção de artifício idêntico. Para noticiar o mesmo crime, a Gazeta de Notícias repetiu, entre os dias 16 e 25 de outubro, pelo menos oito vezes os títulos "O crime da Rua da Carioca" e "Quadrilha da morte". Interessante notar o destaque dado pelos periódicos ao delegado e aos próprios repórteres (ver Figura 5). No dia 24 de outubro, a Gazeta de Notícias publica em sua capa, em quatro colunas, uma foto do delegado encarregado do caso, de seus auxiliares e do escrivão. Ressalta, então, "o realce e brilho do notável” Dr. Caetano Jr, que acabara de demonstrar "seu alto tino policial com o célebre inquérito" (O CRIME..., 24 out. 1906, p. 1). 
Figura 5 - Primeira página do jornal Gazeta de Notícias de 24 de outubro de 1906

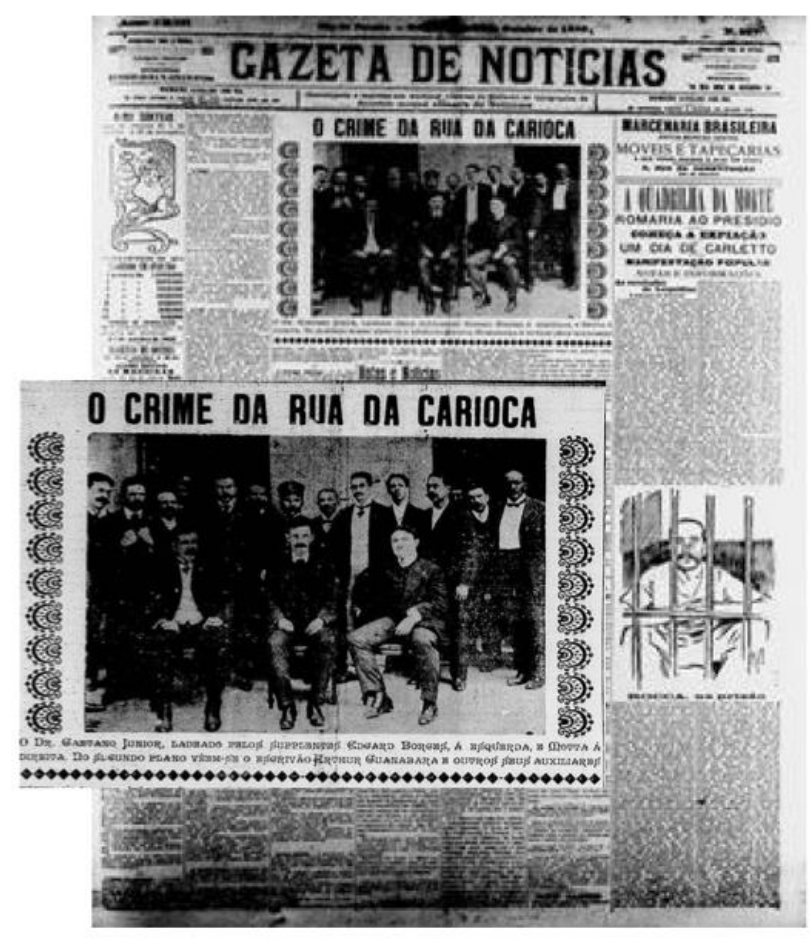

Fonte: Elaboração da autora a partir de imagem da Hemeroteca Digital da Biblioteca Nacional

As notícias sobre crimes ganham o noticiário para conquistar mais leitores e cumprem um papel tal qual os folhetins. Ainda que os personagens sejam retirados da realidade, a estrutura narrativa lembra a dos romances folhetins (BARBOSA, 2007, p. 50), reforçando os mitos. Os crimes entram para o mix dos periódicos, que apresentavam também os resultados do jogo do bicho, notícias de cordões e blocos de carnaval.

A edição da primeira página de 10 de março de 1915 da Gazeta de Notícias também é sintomática do destaque que o noticiário policial recebe no período. A manchete, sobre a Primeira Guerra Mundial, foi publicada em três colunas. Há espaço para outras três notícias na mesma capa. Mas a que mereceu mais destaque foi "A seducção, desonra e roubo não passam de uma fantasia", sobre um crime em São Cristóvão (A SEDUCÇÃO..., 10 mar. 1915 , p. 1). Enquanto a manchete foi publicada em três colunas, a notícia policial foi impressa com mais relevo, em quatro. A página tem, ao todo, sete fotos e o desenho de um mapa (ver Figura 6). 
Figura 6 - Primeira página do jornal Gazeta de Notícias de 10 de março de 1915

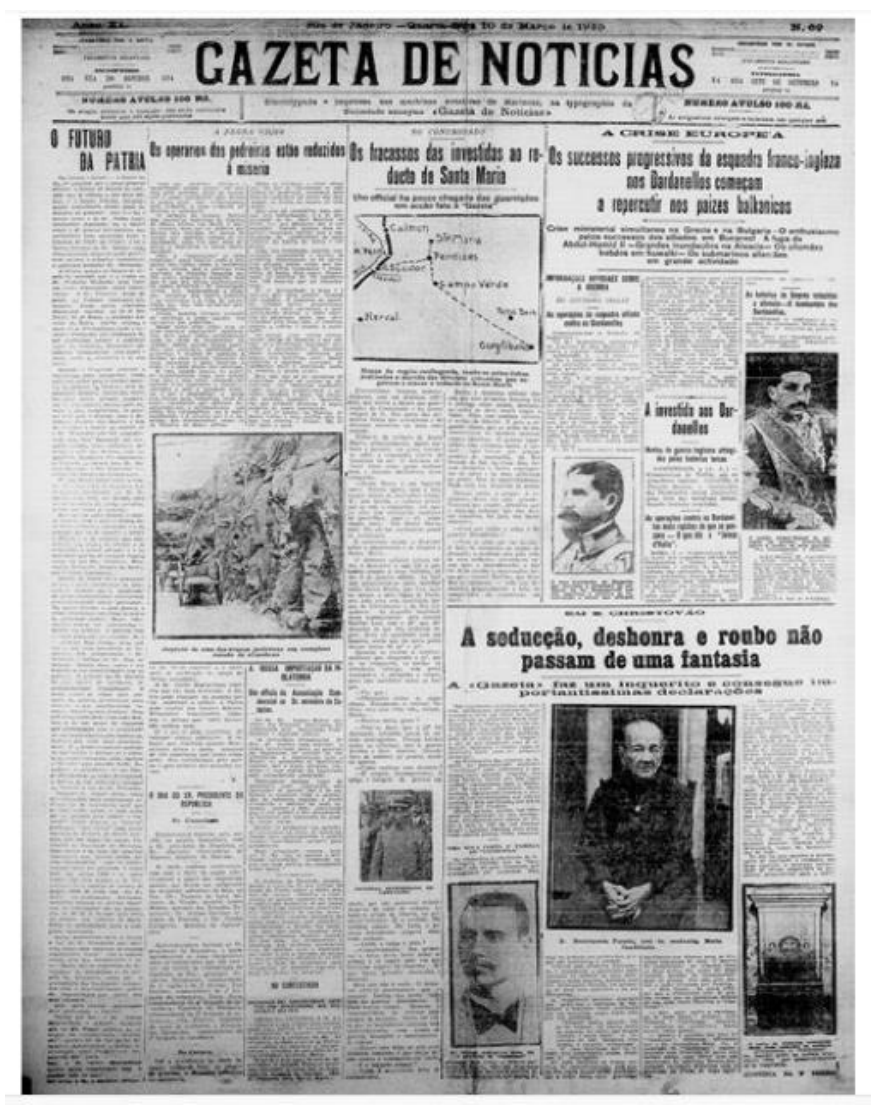

Fonte: Hemeroteca Digital da Biblioteca Nacional

O investimento em apuração já é mais visível, com a ida do repórter a campo com mais frequência, como é revelado tanto em uma notícia sobre operários desempregados quanto na policial acima mencionada. Na notícia policial, o subtítulo aponta: "A Gazeta de Notícias faz um inquérito e consegue importantíssimas declarações". O texto contesta os jornais que noticiaram a morte de Maria Candelária Maia pelo noivo como sendo "fruto de desonra e roubo". O "inquérito" da Gazeta de Notícias consistiu em ouvir a avó da moça, Dona Henriqueta Parada, que negou a versão divulgada e alegou que o término do namoro da neta deveu-se a "incompatibilidade de gênios" (A SEDUCÇÃO..., 10 mar. 1915, p. 1).

Em outra frente para ampliar o público, as promoções invadem a primeira página de $O$ Paiz, em 1906. O jornal promove pelo menos seis concursos, cujos prêmios vão de dinheiro a automóvel. Na primeira página do dia 11 de abril de 1906, o jornal anunciava, envergonhado, o "Concurso da Moda", como uma das "inovações indignas" da imprensa estrangeira, mas com sucesso "brilhantíssimo" (CONCURSO..., 11 abr. 1906, p. 1). As "evoluções do 
jornalismo estrangeiro" a que O Paiz se refere foram lançadas pelos jornais New York World (1860) e Morning Journal (1888), de Joseph Pulitzer e William Hearst, respectivamente, marcos do jornalismo sensacionalista norte-americano. Os dois jornais tinham preços baixos, manchetes com corpo tipográfico destacado e promoviam premiações e sorteios (AMARAL, 2011).

As mudanças verificadas entre 1905 e 1925 nas capas de jornais revelam uma tendência dos periódicos de irem dedicando mais espaço às notícias, e, menos, à opinião. A novidade é que, além da manchete - como já apontado nos exemplos citados - , as notícias deixam de ser agrupadas por temas e ganham títulos próprios em duas ou três colunas. $O$ Estado de S.Paulo e o Jornal do Brasil são exceção no período. O primeiro continua dando destaque à seção "Telegrammas do Exterior", em três colunas, no alto da primeira página. As notícias ainda são dispostas em uma coluna, sem título. No Jornal do Brasil, a capa ainda é totalmente dedicada aos classificados.

A Gazeta de Notícias, o Correio da Manhã e $O$ Paiz têm primeiras páginas movimentadas, com diversas chamadas, fotos e features. ${ }^{12}$ A capa da edição de 10 de outubro de 1925 do Correio da Manhã tem como manchete, ocupando suas então nove colunas, no alto, uma notícia sobre a Guerra do Rife, conflito ocorrido entre 1920 e 1926 entre a Espanha e forças marroquinas das tribos rifenhas e Djebali. Mas é para a única fotografia da página, no estilo feature, que se volta o olhar do leitor. Com o título "O homem que assombra Londres com o esplendor de que se cerca", ocupando duas linhas em duas colunas, a notícia é sobre um marajá hospedado no hotel Savoy, em Londres (ver Figura 7):

O marajá de Patisla tem assombrado Londres com o esplendor de sua vida de forasteiro. Ocupa todo o quinto andar do hotel Savoy, com 100 quartos, tem a sua disposição 20 automóveis e usa um turbante valiosíssimo de seda clara, rodeado de joias, pérolas e diamantes. Seu rendimento anual é calculado em 1.200.000 libras (O HOMEM..., 10 out. 1925, p. 1).

\footnotetext{
12 No jargão jornalístico, são consideradas as noticias interesantes. GANS (1979) classificou as notícias entre importantes e interessantes. As importantes são aquelas que contribuem para dar sentido à responsabilidade social do jornalismo nas democracias ao zelarem pelo interesse público. Já as interessantes são antagônicas às importantes e dependem da capacidade de entreter o público (GOLDING; ELLIOTT, 1979 apud WOLF, 2009, p.205).
}

Revista Brasileira de História da Mídia, São Paulo, v. 10, n. 2, p. 180-201, jul./dez. 2021195 
Figura 7 - Primeira página do jornal Correio da Manhã de 10 de outubro de 1925

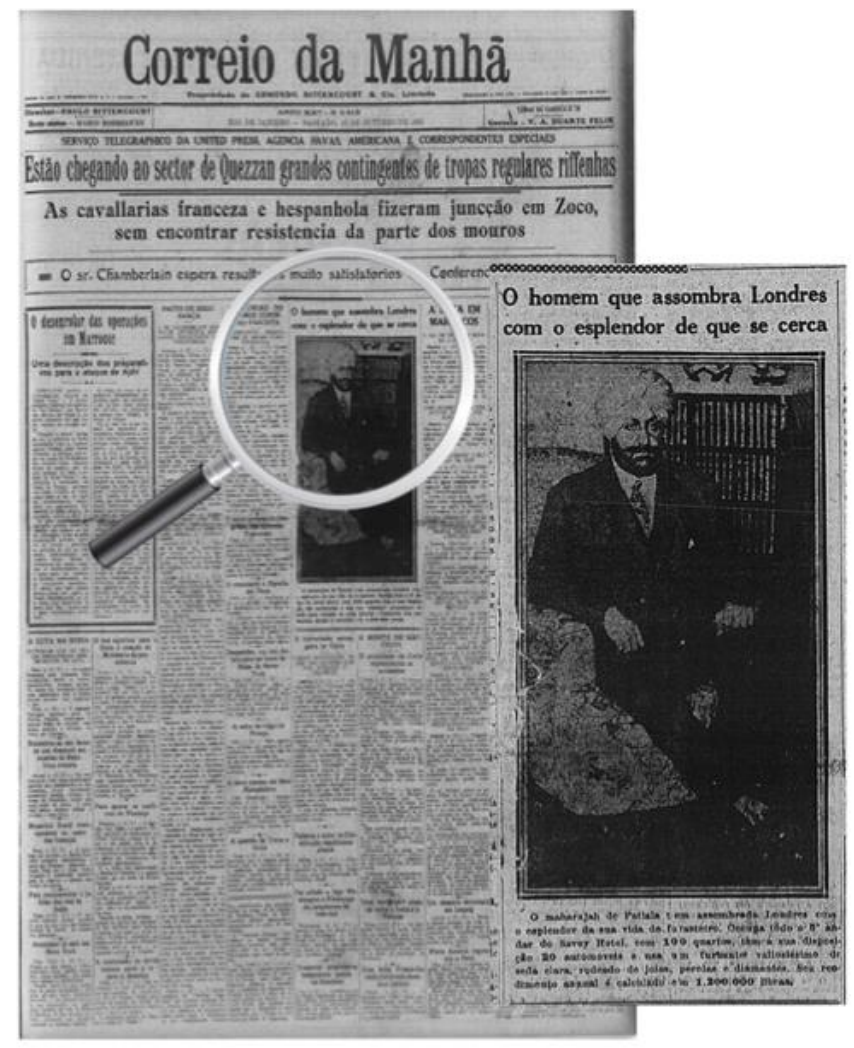

Fonte: Elaboração da autora a partir de imagem da Hemeroteca Digital da Biblioteca Nacional

Se a paginação já é mais dinâmica, o mesmo não se pode falar dos textos. O interessante é notar os diferentes estilos entre as notícias procedentes das agências internacionais e as produzidas pela reportagem local, que ainda não empregavam a técnica do lead. O Paiz, em sua edição de 10 de março de 1925, tem como manchete, no alto, à esquerda: "Na região fabulosa dos garimpos", sobre conflitos entre garimpeiros. O subtítulo vem em quatro linhas: "Através da palavra do coronel Pedro Celestino, presidente do Mato Grosso, conhecemos os antecedentes e pormenores do trágico encontro entre maranhenses e baianos Fala-nos também sobre o assunto o senador Azeredo" (NA REGIÃO..., 10 mar. 1925, p. 1). A leitura do primeiro parágrafo não nos permite saber qual foi o conflito, se há feridos, quais são suas implicações (ver Figura 8).

A notícia ao lado, procedente do exterior, também publicada em três colunas, já está formatada nos padrões que seriam a regra no jornalismo moderno. Sob o título "Grandes descobertas arqueológicas", lê-se "Leptis Magna , a cidade fundada pelos fenícios, na África, ressurge das areias do deserto" (GRANDES..., 10 mar. 1925, p. 1). 
Figura 8 -Primeira página do jornal O Paiz, de 10 de março de 1925

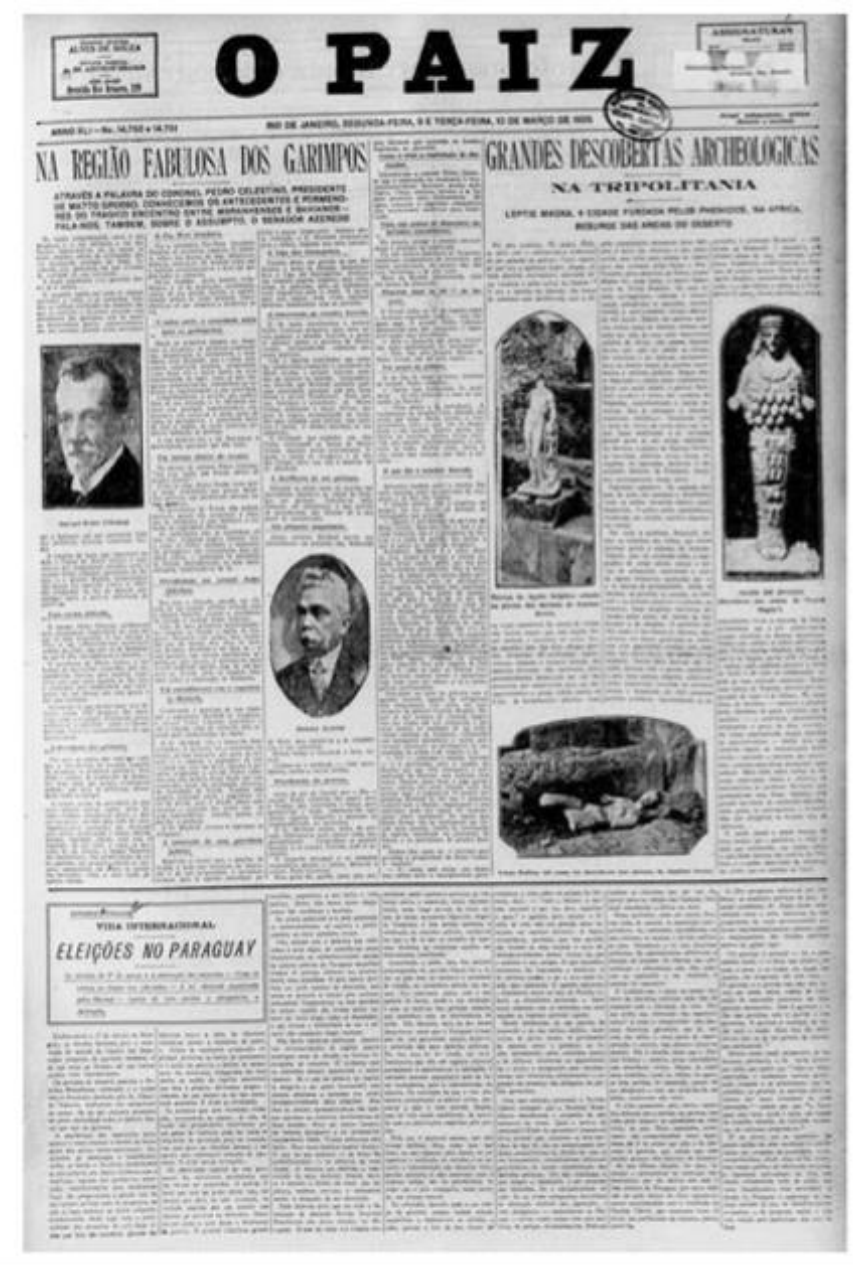

Fonte: Imagem da Hemeroteca Digital da Biblioteca Nacional

Quanto aos artigos de fundo, em 1925 eles já não são estampados nas primeiras páginas, salvo na Gazeta de Notícias. Já consolidado em bases industriais, o novo jornalismo de informação utiliza a primeira página como estratégia comunicacional para atrair mais leitores e alavancar as vendas. Ainda que a venda avulsa fosse "extremamente restrita", a publicidade estivesse em sua fase inicial, e esses jornais ainda dependessem "das benesses do poder público", eles estavam orientados para o lucro (BARBOSA, 2007, p. 48). Seu poder de influência não estava mais voltado para a elite. A estratégia de massificação dos diários dependia de seu conteúdo noticioso, e não mais de sua opinião. 


\section{Considerações finais}

A análise das primeiras páginas durante cinco décadas dos maiores e mais relevantes diários brasileiros entre 1875 e 1925 revelou lentas, mas profundas transformações na passagem do jornalismo de opinião para o jornalismo de informação no país. Foi possível concluir que as origens da primeira página moderna no Brasil remontam a 1905. Naquele ano, notícias começaram a ser diagramadas em duas colunas, sugerindo os primórdios da manchete. No ano seguinte, algumas delas já eram publicadas em quatro colunas.

Em 1915, a primeira página com manchete e outras notícias destacadas, além de fotos e ilustrações, já era uma realidade na Gazeta de Notícias e no Correio da Manhã. Catástrofes, crimes e entrevistas com personalidades ganham destaque, consolidando valores-notícia do jornalismo moderno. Por volta de 1925, a primeira página moderna já estava incorporada em três dos títulos analisados - a Gazeta de Notícias, o Correio da Manhã e O Paiz. As capas são mais dinâmicas e já se vislumbra uma hierarquização entre as notícias. Enquanto a informação invade a primeira página, os artigos de fundo perdem gradativamente destaque, desaparecendo por completo da capa da maioria deles.

A "arqueologia" das primeiras páginas modernas de jornais brasileiros aqui proposta confirma que a consolidação das capas dos periódicos não se deu de forma coesa nem uniforme, e, sim, em meio a rupturas e descontinuidades e em épocas, muitas vezes, distintas. Embora tenha sido observada uma certa "ordem do tempo", ou seja, a predominância de uma determinada arquitetura temporal nos periódicos, essa supremacia coexistiu com outras percepções do tempo no mesmo contexto histórico (POMIAN, 1984), tendo em vista que não houve uma data fundadora para a adoção das manchetes e das primeiras páginas dedicadas às notícias. A pesquisa também permitiu concluir que a "justaposição" (ANDERSON, 1991) e a “colagem" (GIDDENS, 2002), por meio da inclusão progressiva de manchetes, notícias, fotos e ilustrações nas primeiras páginas, refletia a aceleração da vida moderna, na qual o jornalismo de informação se consolidou e da qual se tornou expressão.

\section{Referências}

ANDERSON, Benedict. Imagined communities: reflections on the origin and spread of nationalism. Londres: Verso Editions, 1991.

AMARAL, Márcia Franz. Jornalismo popular. São Paulo: Contexto, 2011. 
ARMSTRONG, Orland Kay. Beginnings of the modern newspaper: a comparative study of St. Louis Dailies from 1875-1925. University of Missouri Bulletin, v. 27, n. 5, p. 1-39, 1926. Journalism $\quad$ Series, $\quad$ n. $39 . \quad$ Disponível em: https://mospace.umsystem.edu/xmlui/handle/10355/54134. Acesso em: 15 fev. 2017.

A SEDUCÇÃO, deshonra e roubo não passam de uma fantasia. Gazeta de Notícias, Rio de Janeiro, p. 1, 10 mar. 1915.

BARBOSA, Marialva. O que a história pode legar aos estudos de jornalismo. Revista

Contracampo, Niterói, n. 12, p. 51-62, 2005. Disponível em: https://periodicos.uff.br/contracampo/article/view/17385. Acesso em: 5 jan. 2017.

BARBOSA, Marialva. História cultural da imprensa: Brasil, 1900-2000. Rio de Janeiro: Mauad X, 2007.

BARBOSA, Marialva. História da Comunicação no Brasil. Petrópolis: Vozes, 2013.

BARSOTTI, Adriana. Primeira página: do grito no papel ao silêncio no jornalismo em rede. 2017. Tese (Doutorado em Comunicação Social) -Pontifícia Universidade Católica do Rio de Janeiro, Rio de Janeiro, 2017.

CONCURSO da Moda. O Paiz, Rio de Janeiro, p. 1, 11 abr. 1906.

FONSECA JR., Wilson Corrêa. Análise de conteúdo. In: DUARTE, Jorge; BARROS, Antonio (org.). Métodos e técnicas de pesquisa em comunicação. São Paulo: Editora Atlas, 2015. p. 280-304

FOUCAULT, Michel. Arqueologia do saber. Rio de Janeiro: Forense Universitária, 2015.

GANS, Herbert. J. Deciding what's news: a study of CBS Evening News, NBC Nightly News, Newsweek and Time. New York: Pantheon Books, 1979.

HOMEM ao mar. Jornal do Brasil, Rio de Janeiro, p. 1, 10 mar. 1905.

GIDDENS, Anthony. Modernidade e identidade. Rio de Janeiro: Zahar, 2002.

GRANDES descobertas arqueológicas. O Paiz, Rio de Janeiro, p. 1, 10 mar. 1925.

KOSELLECK, Reinhart. Futuro passado: contribuição à semântica dos tempos históricos. Rio de Janeiro: Contraponto: Ed. PUC-Rio, 2006.

LEAL, Carlos Eduardo. Correio da Manhã. In: ABREU, Alzira Alves de; BELOCH, Israel; LATTMAN-WELTMAN, Fernando; LAMARÃO, Sérgio Tadeu de Niemeyer. Dicionário Histórico-Biográfico Brasileiro pós-1930. Rio de Janeiro: Fundação Getulio Vargas, 2015. Disponível em: http://www.fgv.br/cpdoc/acervo/arquivo. Acesso em: 10 fev. 2017. 
MARECHAL Floriano. O Paiz, Rio de Janeiro, p. 1, 10 mar. 1895.

MATHEUS, Letícia Cantarela. A movimentação telegráfica de imprensa no século XIX. Postais: Revista do Museu Nacional dos Correios, Brasília, v. 1, n. 1, p. 251-271, jan./jun. 2013. Disponível em: https://issuu.com/culturacorreios/docs/revistapostais_01_2013. Acesso em: 16 fev. 2017.

MULTAS Municipais. Gazeta de Notícias, Rio de Janeiro, p. 1, 10 out. 1875.

NA REGIÃO fabulosa dos garimpos. O Paiz, Rio de Janeiro, p. 1, 10 mar. 1925.

NOITE trágica. Correio da Manhã, Rio de Janeiro, p. 1, 29 out. 1906.

NOTICIARIO. Jornal do Brasil, Rio de Janeiro, p. 1, 10 mar. 1905.

NOTICIARIO. Jornal do Brasil, Rio de Janeiro, p. 1, 11 out. 1905.

O CRIME da rua Carioca. Gazeta de Notícias, Rio de Janeiro, p. 1, 24 out. 1906.

O HOMEM que assombra Londres com o esplendor de que se cerca. Correio da Manhã, Rio de Janeiro, p. 1, 10 out. 1925.

POMIAN, Krzysztof. L’ordre du temps. Paris: Éditions Gallimard, 1984.

RIBEIRO, Ana Paula Goulart. Imprensa e história do Rio de Janeiro dos anos 50. Rio de Janeiro: E-Papers, 2007.

RICOEUR, Paul. Tempo e Narrativa. Campinas: Papirus, 1994. v. 1.

SCHUDSON, Michael. Descobrindo a notícia: uma história social dos jornais nos Estados Unidos. Petrópolis: Vozes, 2010.

SODRÉ, Nelson Werneck. História da imprensa no Brasil. Rio de Janeiro: Mauad, 1999.

SONTAG, Susan. Ensaios sobre a fotografia. Rio de Janeiro: Arbor, 1981.

SUSSEKIND, Flora. Cinematógrafo de letras: literatura, técnica e modernização no Brasil. São Paulo: Companhia das Letras, 1987.

TERREMOTOS na Calábria. Jornal do Brasil, Rio de Janeiro, p. 1, 3 out. 1905.

WIMMER, Roger; D.; DOMINICK, Joseph. Mass media research: an introduction. Wadsworth: Wadsworth Cengage Learning, 2011.

WOLF, Mauro. Teorias da comunicação. Lisboa: Presença, 2009. 
ZUMTHOR, Paul. Performance, recepção, leitura. São Paulo: Cosac Naify, 2014.

Submetido em: 16.02.2020.

Aprovado em: 06.12.2021. 